\title{
CARBON DIOXIDE ABSORPTION INTO AQUEOUS BLENDS OF N-METHYLDIETHANOLAMINE AND 2-ETHYLAMINOETHANOL
}

\author{
Władysław Moniuk*, Ryszard Pohorecki, Piotr Machniewski \\ Warsaw University of Technology, Faculty of Chemical and Process Engineering, Waryńskiego 1, \\ 00-645 Warszawa, Poland
}

\begin{abstract}
Measurements of the absorption rate of carbon dioxide into aqueous solutions of $\mathrm{N}$-methyldiethanoloamine (MDEA) and 2-ethylaminoethanol (EAE) have been carried out. On this basis a mathematical model of the performance of an absorption column operated with aqueous solution of a blend of the above amines at elevated temperatures and pressures have been proposed. The results of simulations obtained by means of this model are described. The work is a part of a wider program, aimed at the development of a new process.
\end{abstract}

Keywords: alkanoloamines, carbon dioxide, absorption, simulation, packed column

\section{INTRODUCTION}

The removal of $\mathrm{CO}_{2}$ from synthesis and flue gases has been gaining increasing interest in the recent years. This is caused by both technological and ecological reasons. The most widespread method of $\mathrm{CO}_{2}$ removal is that of absorption accompanied by a chemical reaction. Among possible reacting solvents, aqueous amine solutions seem to be the most promising. Both single amines and amine blends have been so far proposed for industrial use. The use of mixed amines in gas purification processes is of increasing interest today. The mixed amine systems, which combine higher equilibrium capacity of the tertiary amine with the higher reaction rate of the primary or secondary amine, have been suggested for gas purification processes (Horng and Li, 2002; Liao and Li, 2002; Mandal et al., 2001, 2003; Sun et al., 2005; Ume et al., 2012; Xiao et al., 2000). In many cases the absorption process has to be carried out at elevated temperatures and pressures (e.g. in the case of synthesis gases).

The aim of this work was to check the suitability of selected amines for flue and synthesis gas purification. To this end experimental investigations of the rate of absorption into selected amines, and simulations of the column performance using these amines were carried out. The work is a part of a wider experimental program aimed at the development of a new process.

\section{REACTION MECHANISMS}

\section{1. $\mathrm{MDEA}\left[\mathrm{CH}_{3} \mathrm{CH}_{2}\left(\mathrm{CH}_{2} \mathrm{CH}_{2} \mathrm{OH}\right)_{2} \mathrm{~N}\right]$}

MDEA is a tertiary amine. Reaction mechanisms of primary and secondary amines are different from those of tertiary amines. The following reactions occur during the $\mathrm{CO}_{2}$ absorption into aqueous MDEA solutions (Donaldson and Nguyen, 1980; Rinker et al., 1995).

*Corresponding author, e-mail: w.moniuk@ichip.pw.edu.pl 


$$
\begin{gathered}
\mathrm{CO}_{2}+\mathrm{R}_{3} \mathrm{~N}+\mathrm{H}_{2} \mathrm{O} \stackrel{k_{2 l}, K_{1}}{\longrightarrow} \mathrm{R}_{3} \mathrm{NH}^{+}+\mathrm{HCO}_{3}^{-} \\
\mathrm{CO}_{2}+\mathrm{OH}^{-} \stackrel{k_{22}, K_{2}}{\longleftrightarrow} \mathrm{HCO}_{3}^{-} \\
\mathrm{HCO}_{3}^{-}+\mathrm{OH}^{-} \stackrel{K_{3}}{\longleftrightarrow} \mathrm{CO}_{3}^{2-}+\mathrm{H}_{2} \mathrm{O} \\
\mathrm{R}_{3} \mathrm{NH}^{+}+\mathrm{OH}^{-} \stackrel{K_{4}}{\longleftrightarrow} \mathrm{R}_{3} \mathrm{~N}+\mathrm{H}_{2} \mathrm{O} \\
2 \mathrm{H}_{2} \mathrm{O} \stackrel{\mathrm{K}_{5}}{\longleftrightarrow} \mathrm{OH}^{-}+\mathrm{H}_{3} \mathrm{O}^{+}
\end{gathered}
$$

The rate of reactions (1) and (2) can be expressed as:

$$
\begin{gathered}
r_{1}=k_{21}\left[\mathrm{CO}_{2}\right]\left[\mathrm{R}_{3} \mathrm{~N}\right]-\frac{k_{21}}{K_{1}}\left[\mathrm{R}_{3} \mathrm{NH}^{+}\right]\left[\mathrm{HCO}_{3}^{-}\right] \\
r_{2}=k_{22}\left[\mathrm{CO}_{2}\right]\left[\mathrm{OH}^{-}\right]-\frac{k_{22}}{K_{2}}\left[\mathrm{HCO}_{3}^{-}\right]
\end{gathered}
$$

where

$$
\begin{gathered}
K_{1}=\frac{\left[\mathrm{R}_{3} \mathrm{NH}^{+}\right]\left[\mathrm{HCO}_{3}^{-}\right]}{\left[\mathrm{CO}_{2}\right]\left[\mathrm{R}_{3} \mathrm{~N}\right]} \\
K_{2}=\frac{\left[\mathrm{HCO}_{3}^{-}\right]}{\left[\mathrm{CO}_{2}\right]\left[\mathrm{OH}^{-}\right]}
\end{gathered}
$$

In reactions (3-5) only proton exchange occurs and these reactions can be treated as very fast ("instantaneous"). Equilibrium constants for these reactions are as follows:

$$
\begin{aligned}
K_{3} & =\frac{\left[\mathrm{CO}_{3}^{2-}\right]}{\left[\mathrm{HCO}_{3}^{-}\right]\left[\mathrm{OH}^{-}\right]} \\
K_{4} & =\frac{\left[\mathrm{R}_{3} \mathrm{~N}\right]}{\left[\mathrm{R}_{3} \mathrm{NH}^{+}\right]\left[\mathrm{OH}^{-}\right]} \\
K_{5} & =\left[\mathrm{OH}^{-}\right]\left[\mathrm{H}_{3} \mathrm{O}^{+}\right]
\end{aligned}
$$

Rinker et al. (1995) measured the rate of carbon dioxide absorption into aqueous MDEA solutions in a wetted-sphere absorber. For the interpretation of the obtained results, three different mathematical models, based on Higbie's penetration theory, were used. The first model is the most general model. It includes reactions (1-5) and treats them as reversible reactions. The second model is almost the same as the first model except that it neglects reaction (2). The third model neglects reactions (2-5) and treats reaction (1) as an irreversible pseudo-first-order reaction.

A comparison of the predicted enhancement factor $\mathrm{E}$ from models 1-3 is presented in Fig. 1 (Rinker et al., 1995). As it is seen, for high values of interfacial concentration of $\mathrm{CO}_{2}\left(\sim 10^{-2} \mathrm{kmol} / \mathrm{m}^{3}\right)$ the values of the enhancement factor $\mathrm{E}$ for these 1-3 models, are very close. For the conditions considered in this work $c_{i}=(0.7-1.2) \cdot 10^{-2} \mathrm{kmol} / \mathrm{m}^{3}$, and therefore the simplest, the third model, can be used.

Many studies have been performed on the kinetics of the reaction (1) between MDEA and $\mathrm{CO}_{2}$.

In Fig. 2 the dependence of the reaction rate constant, $k_{21}$, on the amine concentration is presented $\left(t=20{ }^{\circ} \mathrm{C}\right)$. As it is seen, the discrepancies between the results obtained by various authors are very large. The present measurements (Fig. 5) are in agreement with the earlier data of Moniuk and Pohorecki (2000). These data are used in the modelling. 


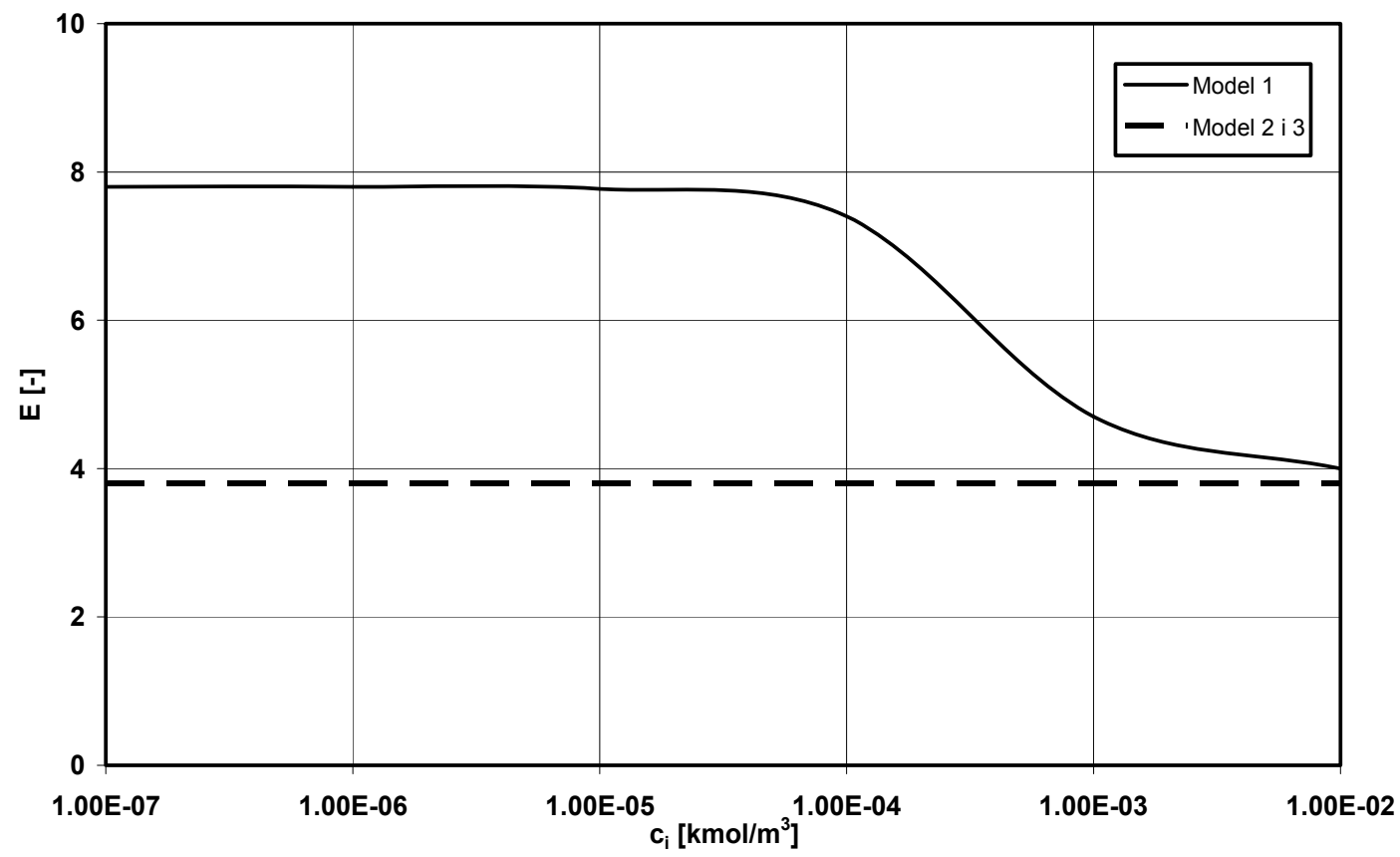

Fig. 1. A comparison of the enhancement factor values, $E$, obtained for models 1-3 (Rinker et al., 1995)

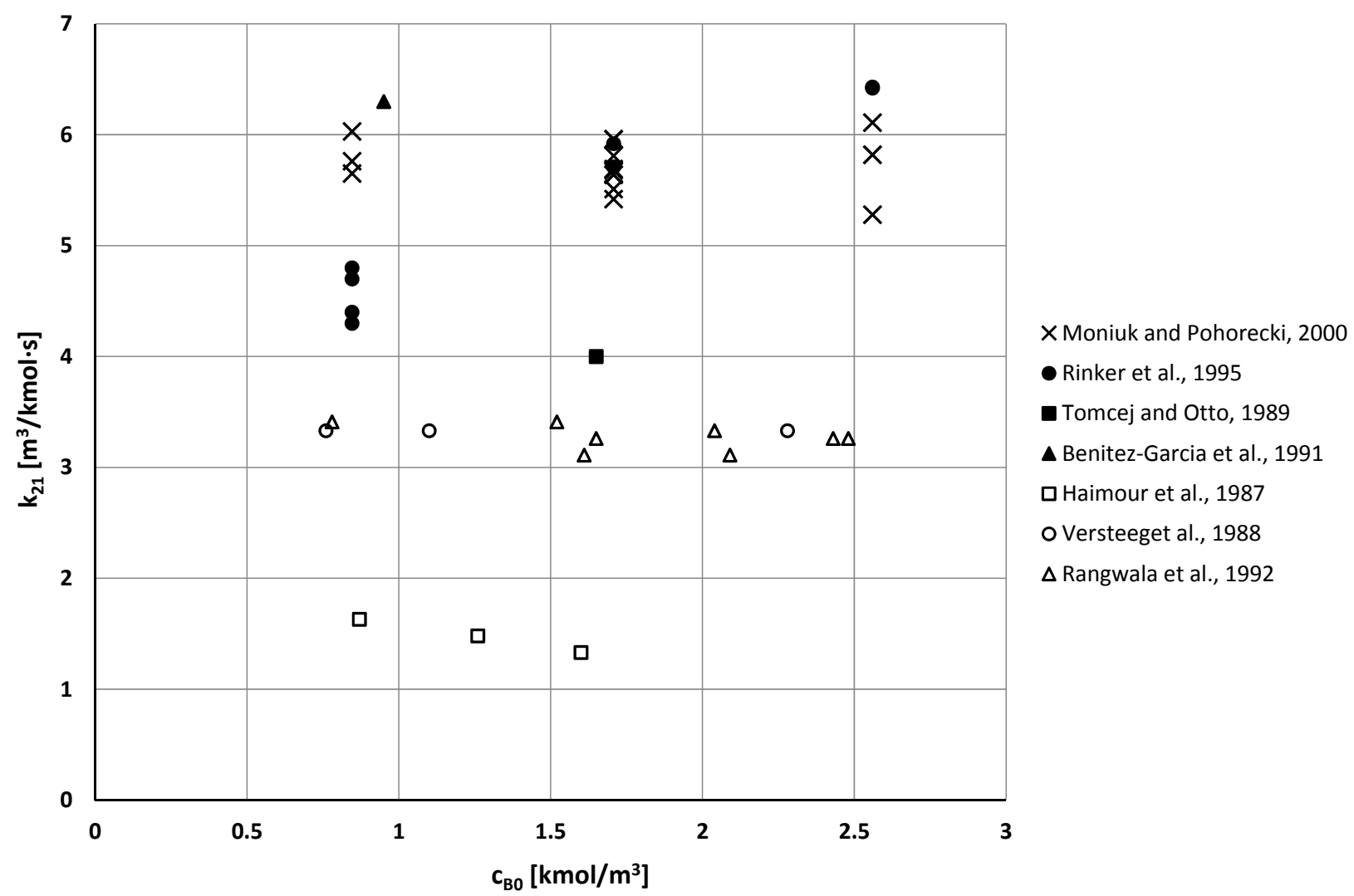

Fig. 2. The dependence of the reaction rate constant, $k_{21}$, on the amine concentration $c_{B o}\left(t=20^{\circ} \mathrm{C}\right)$

\section{2. $\mathrm{EAE}\left[\mathrm{C}_{2} \mathrm{H}_{5} \mathrm{NHC}_{2} \mathrm{H}_{4} \mathrm{OH}\right]$}

EAE is a secondary amine. The reactions of $\mathrm{CO}_{2}$ with primary and secondary alkanolamines in aqueous solutions are believed to take place according to the zwitterion mechanism (Danckwerts, 1979). In this 
mechanism $\mathrm{CO}_{2}$ reacts with amine to form a zwitterion, which further reacts with any base present in the system.

$$
\begin{gathered}
\mathrm{CO}_{2}+\mathrm{R}_{2} \mathrm{NH} \stackrel{k_{2}}{\longleftarrow} R_{2} \mathrm{NH}^{+} \mathrm{COO}^{-} \\
\mathrm{R}_{2} \mathrm{NH}^{+} \mathrm{COO}^{-}+\mathrm{B} \stackrel{k_{B}}{\longleftrightarrow} R_{2} \mathrm{NCOO}^{-}+\mathrm{BH}^{+}
\end{gathered}
$$

If $[z]$ is the concentration of zwitterion (in quasi-steady state) then the rate of $\mathrm{CO}_{2}$ reaction can be expressed as:

$$
r=k_{2}\left[\mathrm{CO}_{2}\right][\mathrm{Am}]-k_{-2}[z]=[z] \sum k_{B}[\mathrm{~B}]
$$

The term $\sum k_{B}[B]$ indicates the contribution of the various bases present in the system to the rate of removal of protons from the zwitterion.

In our case the base (B) may be water of $\mathrm{OH}^{-}$ions. From Eq. (15)

$$
\frac{r}{\left[\mathrm{CO}_{2}\right][\mathrm{Am}]}=\frac{k_{2}}{1+\frac{k_{-2}}{\sum k_{B}[\mathrm{~B}]}}
$$

If $\frac{k_{-2}}{\sum k_{B}[B]}<<1$ we have simple second-order kinetics, as in the case of monoethanolamine (MEA).

If $\frac{k_{-2}}{\sum k_{B}[B]}>>1$ we get

$$
\frac{r}{\left[\mathrm{CO}_{2}\right][\mathrm{Am}]}=\frac{k_{2}}{k_{-2}} \sum k_{B}[\mathrm{~B}]
$$

and we have third-order kinetics as in the case of diethanoloamine (DEA).

There is also an alternative mechanism (termolecular mechanism) proposed by Vaidya and Kenig (2010), but the above (zwitterion) mechanism is more frequently used.

\section{EXPERIMENTAL APPARATUS AND PROCEDURE}

Measurements of the rate of $\mathrm{CO}_{2}$ absorption into aqueous solutions of MDEA and EAE were carried out in a stirred reactor (Autoclave Engineers Inc.) with capacity $1 \cdot 10^{-3} \mathrm{~m}^{3}$. The scheme of the experimental apparatus is shown in Fig. 3.

At the beginning of the experiment, a mixture of gases $\left(\mathrm{CO}_{2}\right.$ and $\left.\mathrm{N}_{2}\right)$ was supplied through the tree-way valve (10) to the $\mathrm{CO}_{2}$ analyser (12). During the main part of the experiment the experimental conditions (pressure, temperature and stirrer speed) were kept constant, and the mixture of gases was supplied through the three - way valve to the gas sparger (8) below the stirrer (9). $\mathrm{CO}_{2}$ concentration at the gas outlet from the reactor was measured by the $\mathrm{CO}_{2}$ analyser (12).

The measurements were carried out under 1-2 bar pressure at the temperature range: $20-70{ }^{\circ} \mathrm{C}$. The other parameters were as follows: stirred speed $700 \mathrm{rpm}$; concentration of $\mathrm{CO}_{2}$ in the inlet gas 46-50 \%vol.; amines concentration: MDEA: 10, 20 and 30 wt.\%; EAE: 1 and 2 wt.\%.

The MDEA was obtained from Sigma - Aldrich with a purity $>98,5$ wt.\%, whereas the EAE was obtained from Aldrich with a purity $>98 \mathrm{wt} . \%$. 


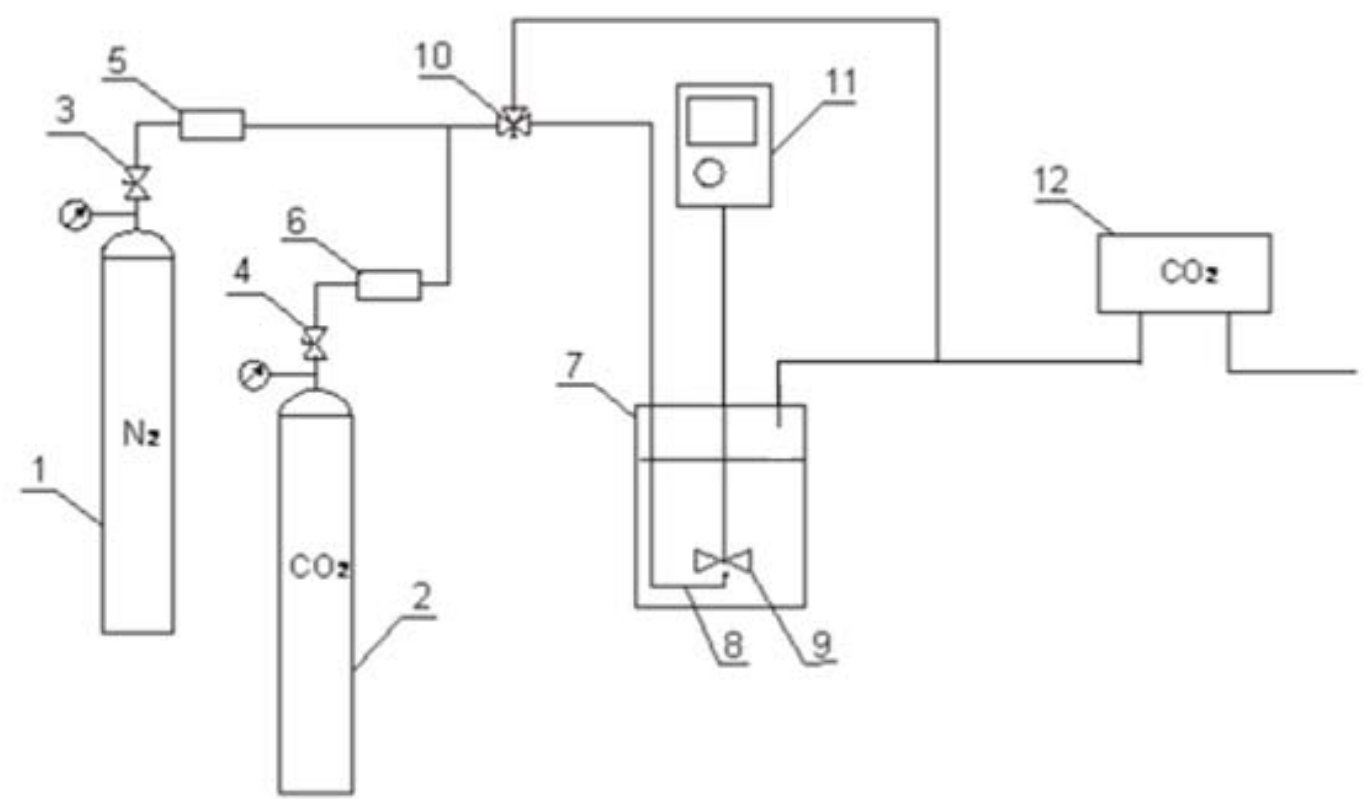

Fig. 3. Scheme of the experimental apparatus

1, 2 - gas cylinders; 3, 4-pressure reducing valves; 5, 6-gas flow meters; 7 - stirred reactor; 8 - sparger; 9 - stirrer; 10 - three - way valve; 11 - temperature, pressure and stirrer speed regulators;

$12-\mathrm{CO}_{2}$ analyser (DCS, Model 300)

On the basis of the $\mathrm{CO}_{2}$ concentrations measured at the gas inlet to the reactor and the gas outlet from the reactor, the rate of $\mathrm{CO}_{2}$ absorption, $R$, was calculated. On the other hand we have:

$$
R=N \cdot a
$$

In the process of absorption with chemical reaction, the molar flux of absorbed $\mathrm{CO}_{2}$ is equal to

$$
N=k_{L}^{*} \cdot c_{A i}
$$

The concentration of $\mathrm{CO}_{2}$ at the interface was calculated from the Henry's law

$$
p_{A i}=H \cdot c_{A i}
$$

The partial pressure of $\mathrm{CO}_{2}$ at the interface, $\mathrm{p}_{\mathrm{Ai}}$, was calculated from the relation

$$
N=k_{g}\left(p_{A o}-p_{A i}\right)=k_{L}^{*} \cdot c_{A i}
$$

The values of the mass transfer coefficient in the gas phase were taken from the Versteeg et al. (1987) data.

For the gas flow in the reactor we assumed plug flow. In this case the average value of the partial pressure of $\mathrm{CO}_{2}$ in the gas phase is equal to

$$
p_{A o}=\frac{\left(p_{\text {Ao(inlet })}-p_{\text {Ao(outlet })}\right)}{\ln \frac{p_{\text {Ao( inlet })}}{p_{\text {Ao( outlet })}}}
$$

\section{RESULTS}

From the $\mathrm{CO}_{2}$ concentrations measured in the gas phase, the rate of $\mathrm{CO}_{2}$ absorption, $\mathrm{R}$ and the mass transfer coefficient with chemical reaction, $k_{L}^{*}$ were calculated. 
Making use of the values of the physical mass transfer in the liquid phase, $k_{L}$, determined experimentally in our earlier work (Moniuk et al., 1997) the values of the enhancement factor, $E$, defined as:

$$
E=\frac{k_{L}^{*}}{k_{L}}
$$

were calculated.

On the other hand, enhancement factor $E$ can be determined from the van Krevelen and Hoftijzer diagram (Ramm, 1976)

$$
E=f(H a, \beta)
$$

where

$$
\begin{gathered}
H a=\frac{\sqrt{k_{21} \cdot c_{B 0} \cdot D_{A}}}{k_{c}} \\
\beta=\frac{c_{B 0} \cdot D_{B}}{b \cdot c_{A i} \cdot D_{A}}
\end{gathered}
$$

For $H a \geq 2$ Porter's relations can be used:

$$
E=1+\beta \cdot\left[1-\exp \left(\frac{-(H a-1)}{\beta}\right)\right]
$$

For a fast pseudo-first-order reaction, when:

$$
\begin{gathered}
k_{L} \leq \sqrt{k_{21} \cdot c_{B 0} \cdot D_{A}} \\
H a \leq \frac{c_{B 0} \cdot D_{B}}{b \cdot c_{A i} \cdot D_{A}}
\end{gathered}
$$

the enhancement factor is equal to the Hatta number value:

$$
E=H \cdot a
$$

Enhancement factor $E$ is thus a function of the Hatta number and the parameter $\beta$. In our case, depending on the values of enhancement factor $E$ and parameter $\beta$, Eqs. (24) or (27) or (30) could be used to determine the values of the enhancement factor, and finally the reaction rate constant, $k_{21}$ or $k_{2}$ values were calculated by comparison with Eq. (23).

\subsection{System: $\mathrm{CO}_{2}-\mathrm{MDEA}$ (tertiary amine)}

In Fig. 4 the dependence of the reaction rate (1) constant $k_{21}$ on the amine concentration for various temperatures is presented.

In Fig. 5 the Arrhenius plot $\left(\log k_{2 l}=\mathrm{f}(1 / T)\right)$ is presented. As it is seen the values $k_{2 l}$ practically do not depend on the amine concentration. The straight line can be described by the relation:

$$
\log k_{21}=10.25-(2792.3 / T)
$$




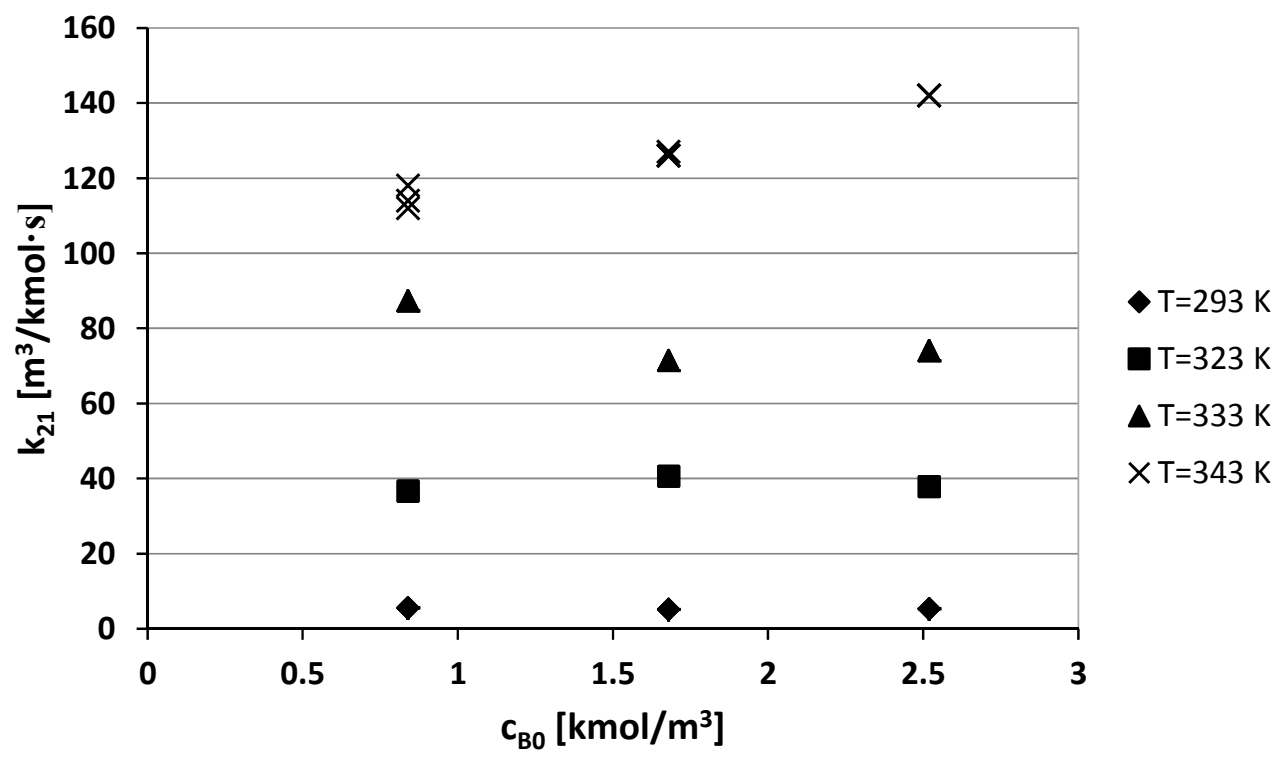

Fig. 4. The dependence of the reaction (1) rate constant $k_{21}$ on the amine (MDEA) concentration for various temperatures

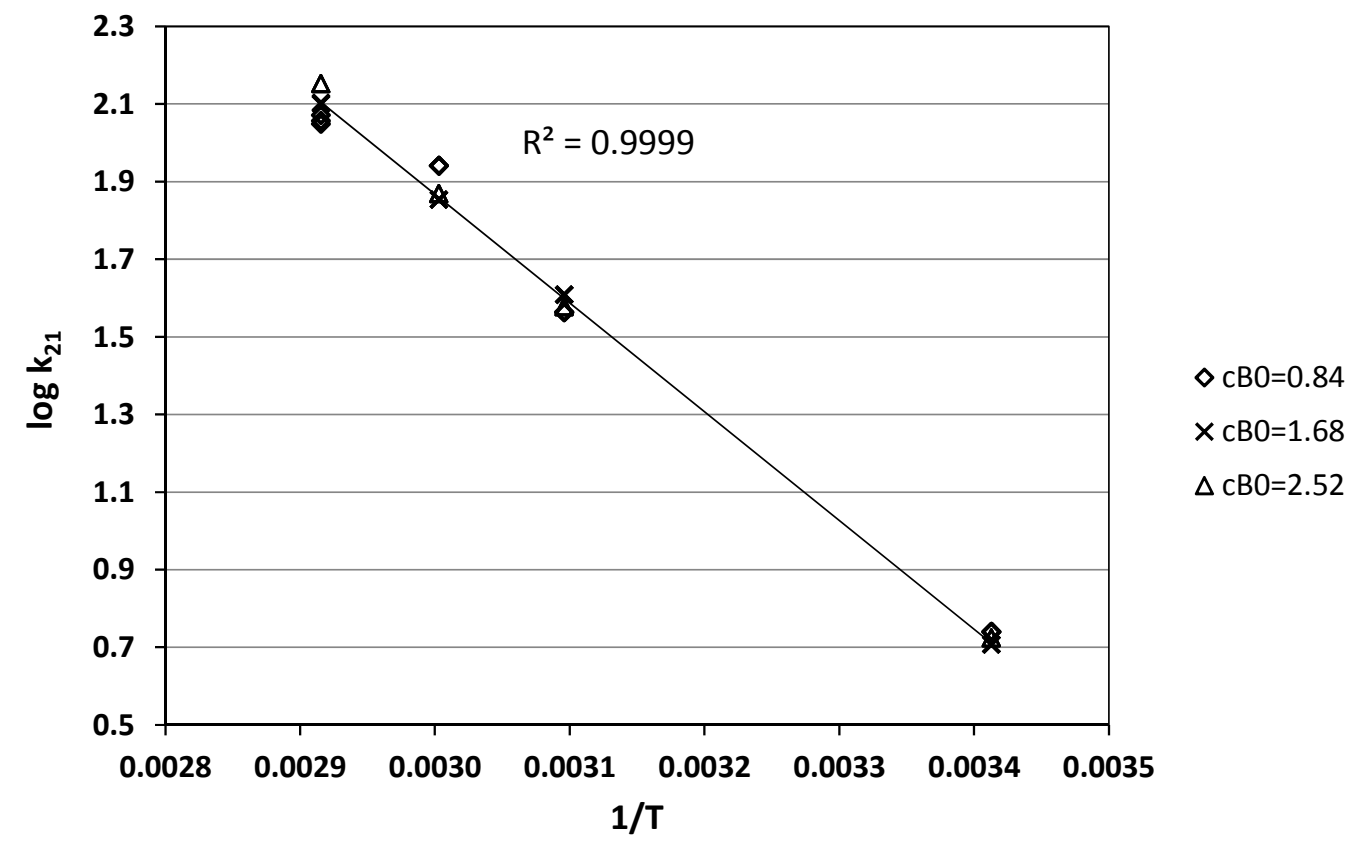

Fig. 5. The Arrhenius plot $\log k_{2 l}=\mathrm{f}(1 / T)$

\subsection{System: $\mathrm{CO}_{2}-\mathrm{EAE}$ (secondary amine)}

The values of the reaction (13) rate constant $k_{2}$ were calculated in a similar way as the reaction (1) constant, $k_{21}$. In Fig. 6 the dependence of the reaction (13) rate constant $k_{2}$ on the amine concentration for various temperatures is presented. In Fig. 7 the Arrhenius plot $\left(\log k_{2}=\mathrm{f}(1 / T)\right)$ is presented. The straight line can be described by the relation:

$$
\log k_{2}=10.052-(1929.8 / T)
$$

The obtained data on the reaction rate constants $k_{21}\left(\mathrm{CO}_{2}-\mathrm{MDEA}\right.$ system $)$ and $k_{2}\left(\mathrm{CO}_{2}\right.$-EAE system) were used for simulation of $\mathrm{CO}_{2}$ absorption into aqueous solutions of a blend of both amines. 


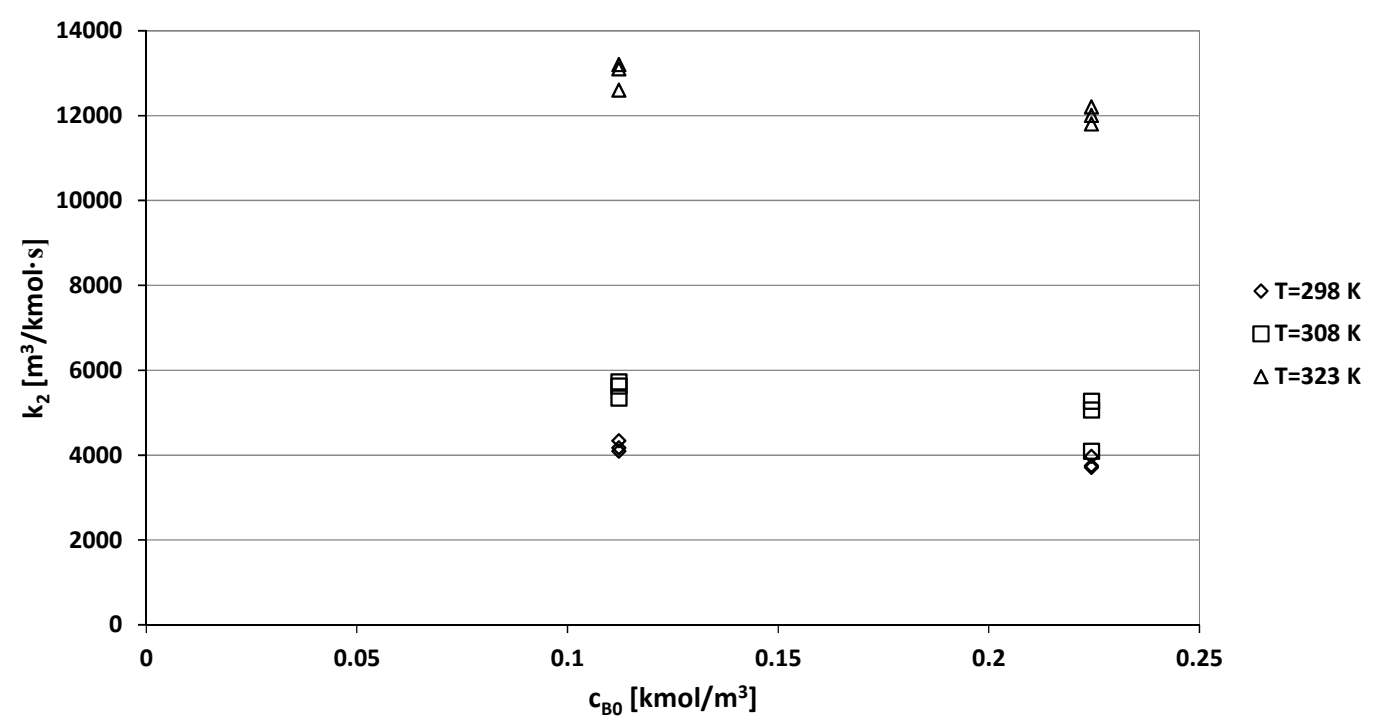

Fig. 6. The dependence of the reaction (13) rate constant, $k_{2}$, on the amine (EAE) concentration for various temperatures

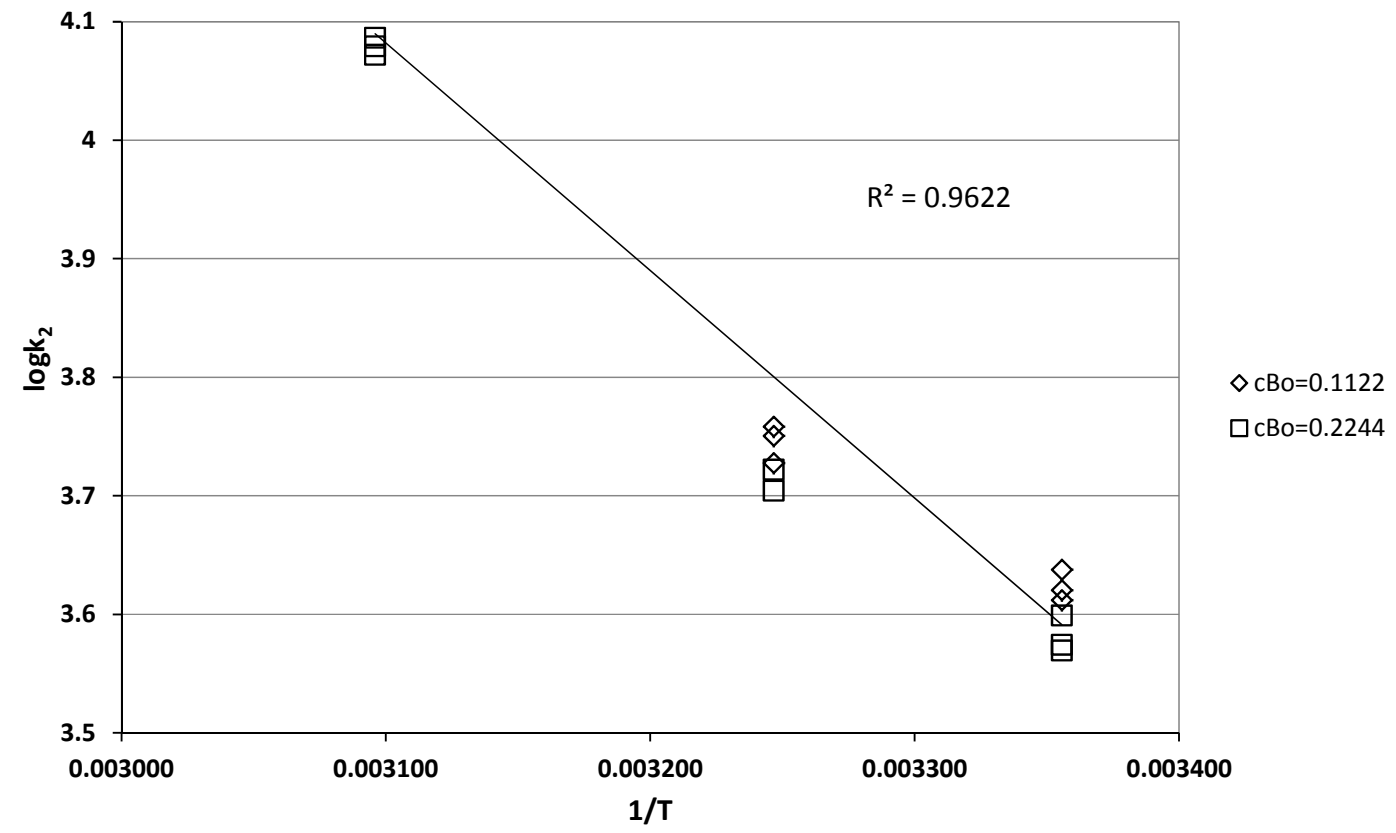

Fig. 7. The Arrhenius plot $\log k_{2}=\mathrm{f}(1 / T)$

\section{MATHEMATICAL MODEL OF $\mathrm{CO}_{2}$ ABSORPTION INTO AQUEOUS ALKANOLAMINE SOLUTIONS}

In order to estimate the performance of an absorption process in a solvent containing the mixture of both amines, a rate-based mathematical model of a packed column has been used. For the process of absorption with a chemical reaction of the type:

$$
A+b B \leftrightarrow d D
$$

The differential equation for the rate of absorption in a counter-current packed column can be written as follows (Danckwerts, 1970):

$$
R_{A} \cdot a \cdot d h=d\left(G_{O M} \cdot x_{A}\right)
$$


For a dilute gas phase we have:

$$
d\left(G_{O M} \cdot x\right) \cong \frac{G_{O M}}{1-x_{A}} d x_{A}
$$

Hence, from Eq. (34) and (35) we have:

$$
\frac{d x_{A}}{d h}=\frac{1-x_{A}}{G_{O M}} R_{A} \cdot a
$$

In the heat balance one should consider heat exchange between phases, heat effects of absorption, reaction and solvent evaporation (or condensation), as well as heat losses to the environment.

In the case of heat exchange between phases, one can neglect the heat transfer resistance in the liquid phase (Sherwood and Pigford, 1952). Thus we have:

$$
d N_{t}=\alpha_{g} \cdot a\left(T_{g}-T_{l}\right) d h
$$

From the heat balance

$$
d N_{t}=d\left(G_{O M} \cdot C_{P} \cdot T_{g}\right) \cong G_{O M} \cdot C_{P} \cdot d T_{g}
$$

Hence

$$
\frac{d T_{g}}{d h}=\frac{\alpha_{g} \cdot a}{C_{P} \cdot G_{O M}}\left(T_{g}-T_{l}\right)
$$

The heat transfer coefficient can be determined from heat and mass transfer analogy

$$
\frac{N u_{g}}{S h_{g}}=\frac{A \cdot R e_{g}^{B} \cdot P r_{g}^{C}}{A \cdot R e_{g}^{B} \cdot S c_{g}^{C}}=\left(\frac{P r_{g}}{S c_{g}}\right)^{C}
$$

Assuming $C=0.33$ (Sherwood and Pigford, 1952) and making use of the definitions of Prandtl and Schmidt numbers we have:

$$
\alpha_{g}=k_{g}\left(\frac{\lambda_{g}}{D_{g}}\right)^{0,66} \cdot\left(C_{p} \cdot \rho_{g}\right)^{0,33}
$$

Hence

$$
\frac{d T_{g}}{d h}=\frac{k_{g} \cdot a}{G_{O M}}\left(\frac{\lambda_{g}}{C_{p} \cdot D_{g}}\right)^{0,66} \cdot \rho_{g}^{0,33} \cdot\left(T_{g}-T_{l}\right)
$$

In the case of solvent evaporation, one can neglect the mass transfer resistance in the liquid phase. Thus we have:

$$
d N=k_{g w} \cdot a \cdot\left(p_{w}-p_{w r}\right) d h=k_{g} \cdot a \cdot P \cdot\left(x_{w}-x_{w r}\right) d h
$$

and

$$
d N=d\left(G_{O M} \cdot x_{w}\right) \cong d\left(\frac{G_{M}}{1-x_{w}} \cdot x_{w}\right)=G_{M} d\left(\frac{x_{w}}{1-x_{w}}\right)=G_{M} \frac{d x_{w}}{\left(1-x_{w}\right)^{2}}=G_{O M} \frac{d x_{w}}{1-x_{w}}
$$

Hence 


$$
\frac{d x_{w}}{d h}=\frac{k_{g w} \cdot a \cdot P \cdot\left(1-x_{w}\right)}{G_{O M}}\left(x_{w}-x_{w r}\right)
$$

The heat effect of solvent evaporation is equal to the product of the heat of vaporization $\left(q_{W}\right)$ and the amount of evaporated solvent. The heat effect of absorption and reaction is equal to the product of the overall heat of absorption and reaction $\left(q_{A}\right)$ and the amount of absorbed component. In these conditions the heat balance can be written as follows (Hobler, 1968)

$$
\frac{d T_{l}}{d h}=\frac{G_{O M}}{L_{O} \cdot c_{l}} \cdot\left(-C_{p} \frac{d T_{g}}{d h}+q_{w} \frac{d x_{\mathrm{H}_{2} \mathrm{O}}}{d h}+q_{r} \frac{d x_{\mathrm{CO}_{2}}}{d h}\right)+\frac{q_{s}}{L_{o} \cdot c_{l}}
$$

The simulations of $\mathrm{CO}_{2}$ absorption into aqueous alkanoloamines solutions in the packed column consisted in simultaneous numerical integrations of the following equations:

- Eqs. (36) and (45) describing the concentration profiles of the absorbed component $x_{A}$ and the solvent vapour $x_{W}$ in the gas phase;

- Eqs (42) and (46) describing the temperature profiles in the gas $\left(T_{g}\right)$ and liquid $\left(T_{l}\right)$ phases;

- Eqs (47) and (48) describing the profiles of gas (Go) and liquid $\left(L_{o}\right)$ flow rates

For the dilute gas phase

$$
\frac{d G_{o}}{d h}=M_{A} G_{o M} \frac{d x_{A}}{d h}+M_{W} G_{o M} \frac{d x_{W}}{d h}
$$

For the counter-current flow

$$
\frac{d L_{o}}{d h}=\frac{d G_{o}}{d h}
$$

\section{RESULTS OF SIMULATIONS}

A computer program for the numerical integration of Eqs. (38), (42), (45), (46), (47) and (48) along the column height has been developed in MATLAB environment. The rate of $\mathrm{CO}_{2}$ absorption in packed column can be calculated from the relation (Pohorecki et al., 1978, 1990; Moniuk 2006)

$$
R_{A}=\left(x_{A} \cdot P-p_{A r}\right) \frac{H \cdot \sqrt{D_{A} \cdot k_{1}+k_{l}^{2}}}{1+\frac{H \cdot \bar{R} \cdot T}{k_{g}} \cdot \sqrt{D_{A} \cdot k_{l}+k_{l}^{2}}}
$$

The pseudo-first-order reaction rate constant, $k_{l}$ is equal to:

$$
k_{1}=k_{21(M D E A)}[M D E A]+k_{2[E A E]}[E A E]
$$

The simulations were carried out for the following industrially important conditions (Pohorecki et al., 1979, 1990; Moniuk 2006):

- height of column: 20-30 m

- column diameter: $2 \mathrm{~m}$

- packing of column: steel Pall rings

- pressure: 20 - 25 bar

- liquid temperature at the inlet to the column (top): $70-110^{\circ} \mathrm{C}$

- gas temperature at the inlet to the column (bottom): $70-110^{\circ} \mathrm{C}$

- mole fraction of $\mathrm{CO}_{2}$ in the gas inlet: $x_{A}=0.18-0.20$

- liquid flow: $345 \mathrm{~m}^{3} / \mathrm{h}$ 
- gas flow: $79000 \mathrm{~m}^{3} / \mathrm{h}$ (in normal conditions)

- amines concentration: MDEA: 30 wt.\%, EAE: 2 wt.\%.

Mass transfer coefficient in the gas phase, $k_{g}$, was calculated from Gildenblat correlation (Pohorecki et al., 1978; Ramm, 1976); mass transfer coefficient in the liquid phase $k_{L}$ was calculated from Sherwood and Holloway correlation (Hobler, 1962; Pohorecki et al., 1978). The overall heat of absorption and reaction in aqueous MDEA solution is equal to $q_{R}=48.6 \mathrm{~kJ} / \mathrm{mol}$ (Critchfield and Rochelle, 1987).

The heat of solvent vaporization was calculated from Watson relation (Pohorecki et al., 1978)

$$
q_{w}=40.62 \cdot\left(2.3615-\frac{T}{274.1}\right)^{0.38}
$$

Some simulation results are presented in Figs. $8-11$.
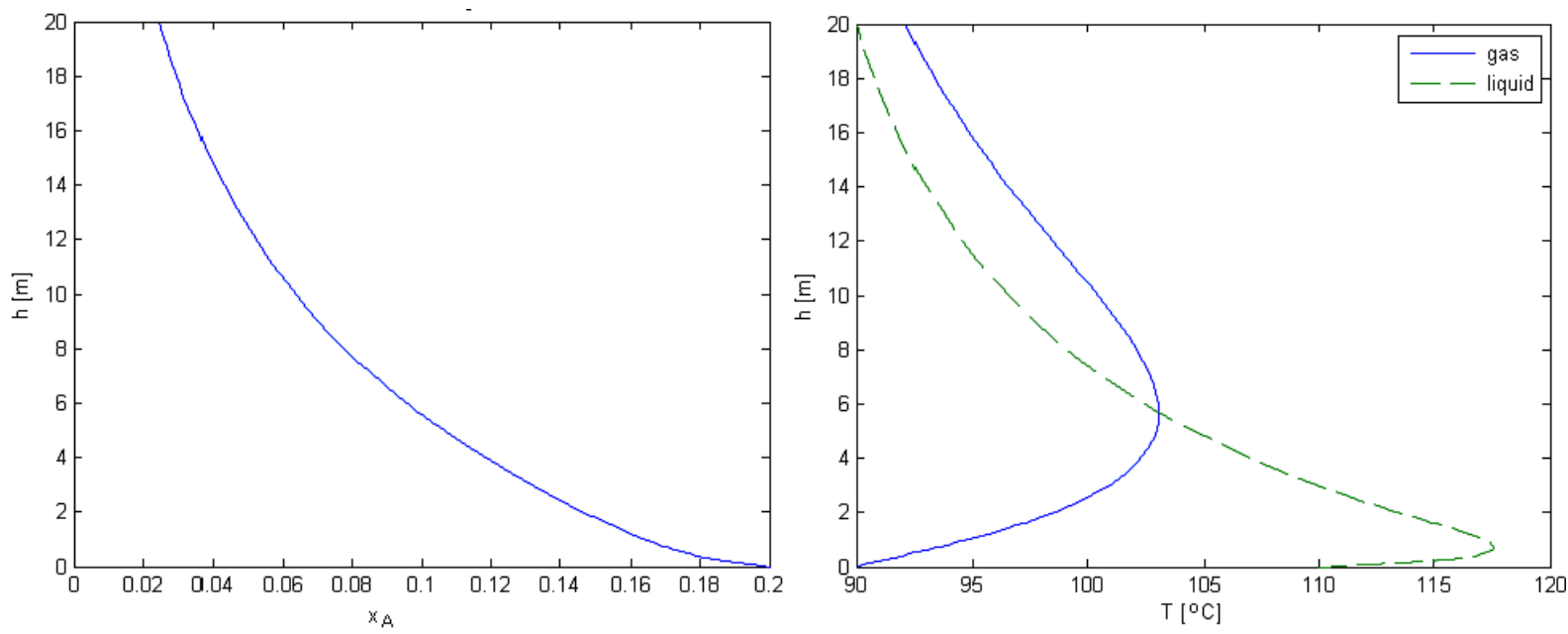

Fig. 8. Profiles of $\mathrm{CO}_{2}$ mole fraction in the gas phase, $\left(x_{A}\right)$ and gas and liquid temperatures $(T)$ along the column height, $h ; P=20$ bar, $T_{g}=90, T_{L}=90,30 \mathrm{wt} . \% \mathrm{MDEA}+2 \mathrm{wt} . \% \mathrm{EAE}$
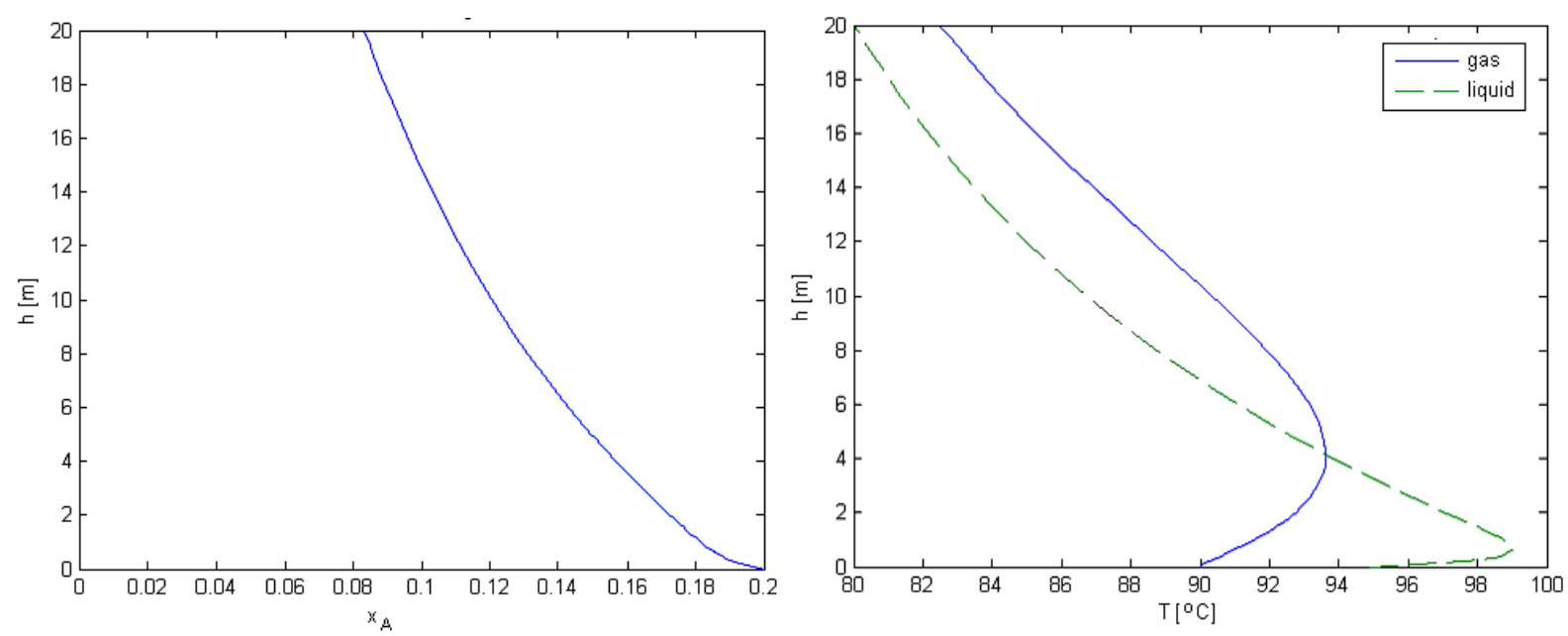

Fig. 9. Profiles of $\mathrm{CO}_{2}$ mole fraction in the gas phase, $\left(x_{A}\right)$ and gas and liquid temperatures $(T)$ along the column height, $h ; P=20$ bar, $T_{g}=90, T_{L}=80,30 \mathrm{wt} . \%$ MDEA $+0 \mathrm{wt} . \%$ EAE 

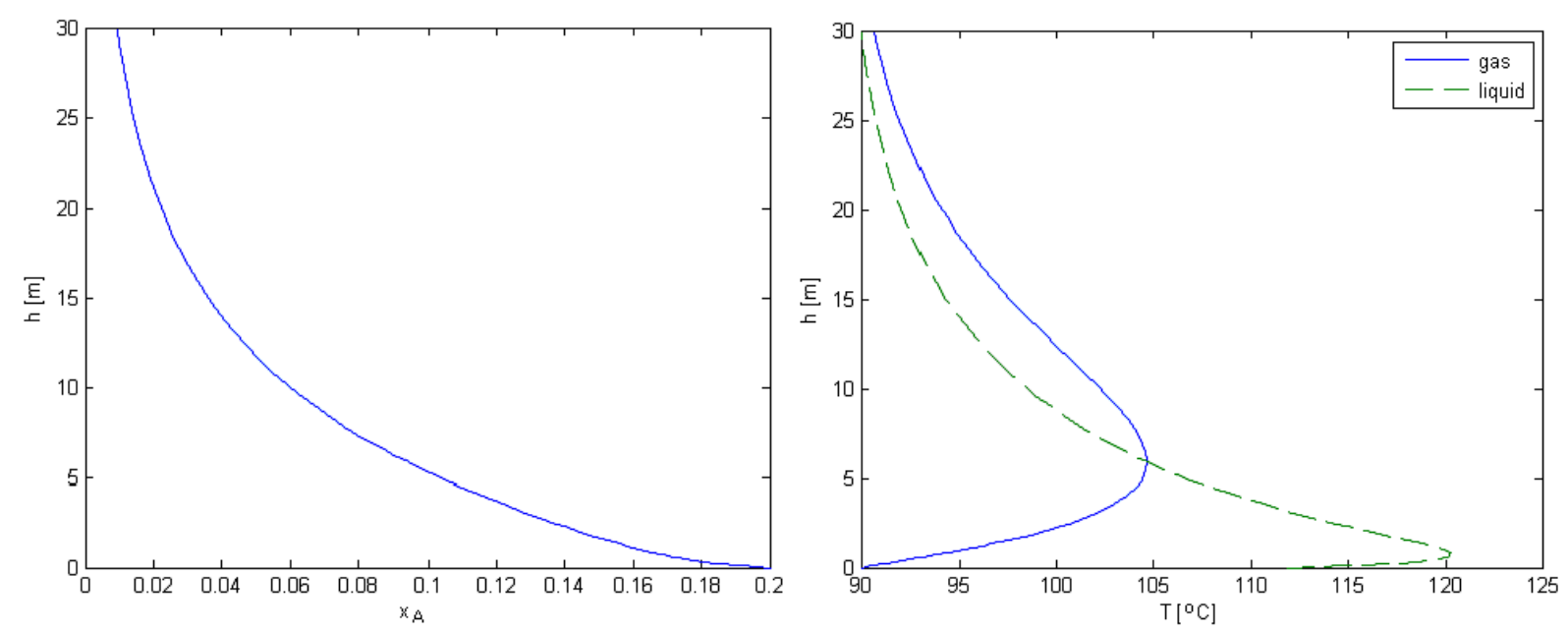

Fig. 10. Profiles of $\mathrm{CO}_{2}$ mole fraction in the gas phase, $\left(x_{A}\right)$ and gas and liquid temperatures $(T)$ along the column height, $h ; P=20$ bar, $T_{g}=90, T_{L}=90,30 \mathrm{wt} . \% \mathrm{MDEA}+2 \mathrm{wt} . \% \mathrm{EAE}$
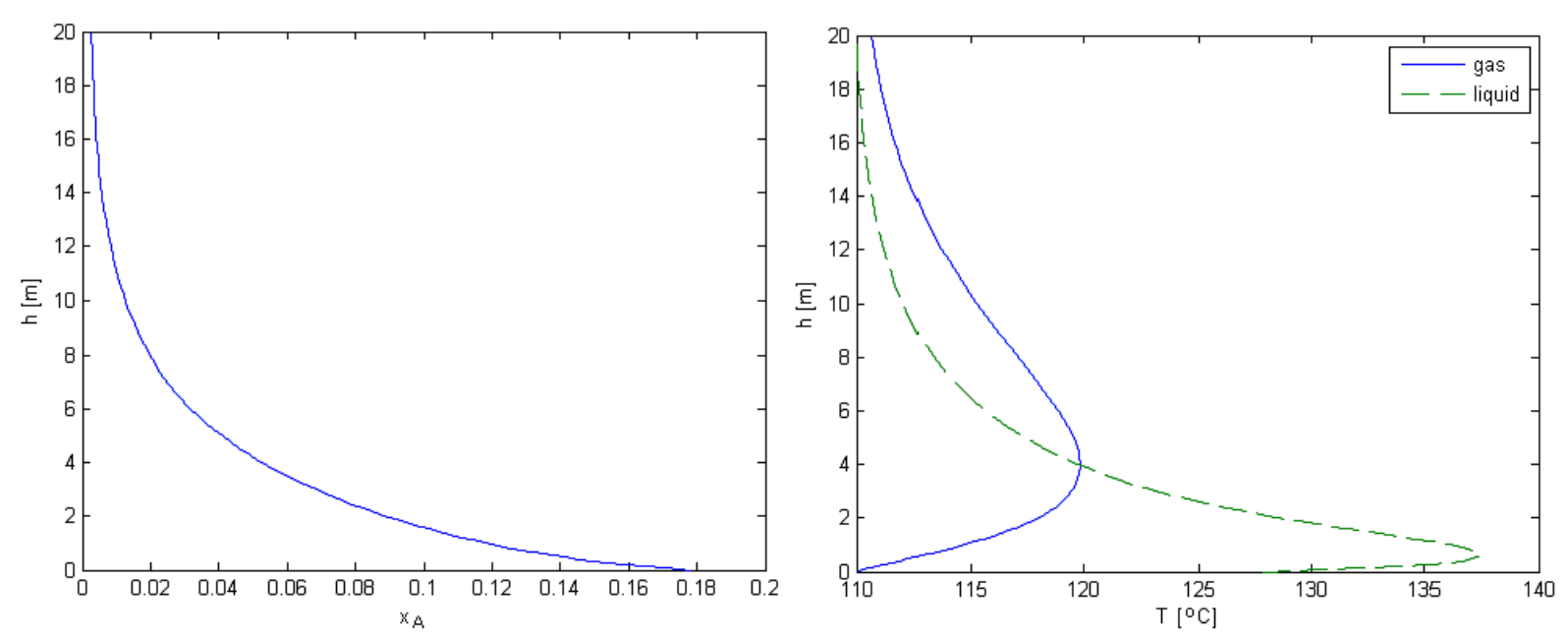

Fig. 11. Profiles of $\mathrm{CO}_{2}$ mole fraction in the gas phase, $\left(x_{A}\right)$ and gas and liquid temperatures $(T)$ along the column height, $h ; P=25$ bar, $T_{g}=110, T_{L}=110,30 \mathrm{wt} . \%$ MDEA $+2 \mathrm{wt} . \%$ EAE

In order to determine the most suitable conditions for an industrial process, similar calculations have been carried out for a range of gas and liquid temperatures.

It has been found that absorption efficiency of $\mathrm{CO}_{2}$ practically does not depend on the gas temperature but significantly depends on the liquid temperature. It is therefore important to note, that there is a significant temperature increase at the bottom of the column where the rate of $\mathrm{CO}_{2}$ absorption is the highest. It is the result of the high value of the overall heat of absorption and reaction of $\mathrm{CO}_{2}$ in aqueous MDEA solutions.

Absorption efficiency significantly depends on EAE concentration. In similar conditions where $c_{E A E}=0$ wt.\% (Fig. 9) the mole fraction of $\mathrm{CO}_{2}$ at the top of the column decreases only to $8.4 \%$ (Fig. 9). For the column height of $30 \mathrm{~m}$ (Fig. 10) $\mathrm{CO}_{2}$ concentration decreases to $1 \%$. In conditions similar to the industrial BENFIELD process $\left(\mathrm{CO}_{2}\right.$ absorption into aqueous potash solutions with DEA, $P=25$ bar, $t_{L}$ at the bottom of the column $\left.=110{ }^{\circ} \mathrm{C}, x_{A}=0.178\right)$ the mole fraction of $\mathrm{CO}_{2}$ at the top of the column decreases to $0.018 \%$ (Fig. 11) 
It has been concluded that the new solvent (aqueous 30\% MDEA solutions with 2\% EAE) may be promising in the process of gas purification in ammonia production. This solvent has been registered for a patent (Polish Patent Application P391333).

\section{CONCLUSIONS}

In order to develop a new process of synthesis and flue gases purification the measurements of the rate of $\mathrm{CO}_{2}$ absorption into aqueous of MDEA and EAE were carried out in a stirred reactor and the reaction rate constants between $\mathrm{CO}_{2}$ and alkanoloamines were determined.

On this basis a mathematical model for the performance of an absorption column operated with aqueous solution of a blend of the above amines at elevated temperatures and pressures has been developed. The results of simulations obtained by means of this model are described.

The work is a part of a wider program, aimed of the development of a new technological process.

\section{SYMBOLS}

$\begin{array}{ll}A, B, D & \text { components } \\ A m & \text { amine } \\ a & \text { interfacial area per unit volume of packing, } \mathrm{m}^{2} / \mathrm{m}^{3} \\ B & \text { base } \\ b & \text { stoichiometric coefficient } \\ C_{P} & \text { molar heat capacity of the gas, } \mathrm{kJ} /(\mathrm{kmol} \cdot \mathrm{K}) \\ c & \text { molar concentration, } \mathrm{kmol} / \mathrm{m}^{3} \\ c_{B o} & \text { amine concentration, } \mathrm{kmol} / \mathrm{m}^{3} \\ c_{l} & \text { heat capacity of the solution, } \mathrm{kJ} /(\mathrm{kg} \cdot \mathrm{K}) \\ D E A & \text { diethanolamine } \\ D_{A} & \text { diffusivity of the absorbed component in the liquid phase, } \mathrm{m}^{2} / \mathrm{s} \\ D_{B} & \text { diffusivity of the liquid component in the liquid phase, } \mathrm{m}^{2} / \mathrm{s} \\ D_{g} & \text { diffusivity of the absorbed component in the gas phase, } \mathrm{m}^{2} / \mathrm{s} \\ d & \text { stoichiometric coefficient } \\ E A E & 2 \text { ethylaminoethanol } \\ E & \text { enhancement factor } \\ G_{O} & \text { mass gas flow rate per unit column area, } \mathrm{kg} /\left(\mathrm{m}^{2} \cdot \mathrm{s}\right) \\ G_{M} & \text { molar inert gas flow rate per unit column area, } \mathrm{kg} /\left(\mathrm{m}^{2} \cdot \mathrm{s}\right) \\ G_{O M} & \text { molar gas flow rate per unit column area, } \mathrm{kg} /\left(\mathrm{m}^{2} \cdot \mathrm{s}\right) \\ h & \text { packing height, } \mathrm{m} \\ H & \text { Henry’s constant, } \mathrm{kmol} /\left(\mathrm{m}^{3} \cdot \text { bar }\right) \\ H a & \text { Hatta number } \\ K_{i} & \text { equilibrium reaction (i) constant } \\ k_{L} & \text { liquid-film mass transfer coefficient, } \mathrm{m} / \mathrm{s} \\ k_{L}^{*} & \text { liquid-film mass transfer coefficient with chemical reaction, } \mathrm{m} / \mathrm{s} \\ k_{g} & \text { gas-film mass transfer coefficient, } \mathrm{kmol} /\left(\mathrm{m}^{2} \mathrm{~s} \mathrm{bar}\right) \\ k_{l} & \text { pseudo-first-order reaction rate constant, } 1 / \mathrm{s} \\ k_{2} & \text { reaction }(13) \text { rate constant }(\text { from left side to right side }), \mathrm{m}^{3} /(\mathrm{kmol} \cdot \mathrm{s}) \\ k_{-2} & \text { reaction }(13) \text { rate constant }(\text { from right side to left side }), \mathrm{m}^{3} /(\mathrm{kmol} \cdot \mathrm{s}) \\ k_{21} & \text { reaction }(1) \text { rate constant, } \mathrm{m}^{3} /(\mathrm{kmol} \cdot \mathrm{s}) \\ k_{22} & \text { reaction (2) rate constant, } \mathrm{m}^{3} /(\mathrm{kmol} \cdot \mathrm{s}) \\ L_{o} & \text { mass liquid flow rate per unit column area, } \mathrm{kg} /\left(\mathrm{m}^{2} \cdot \mathrm{s}\right) \\ & \end{array}$




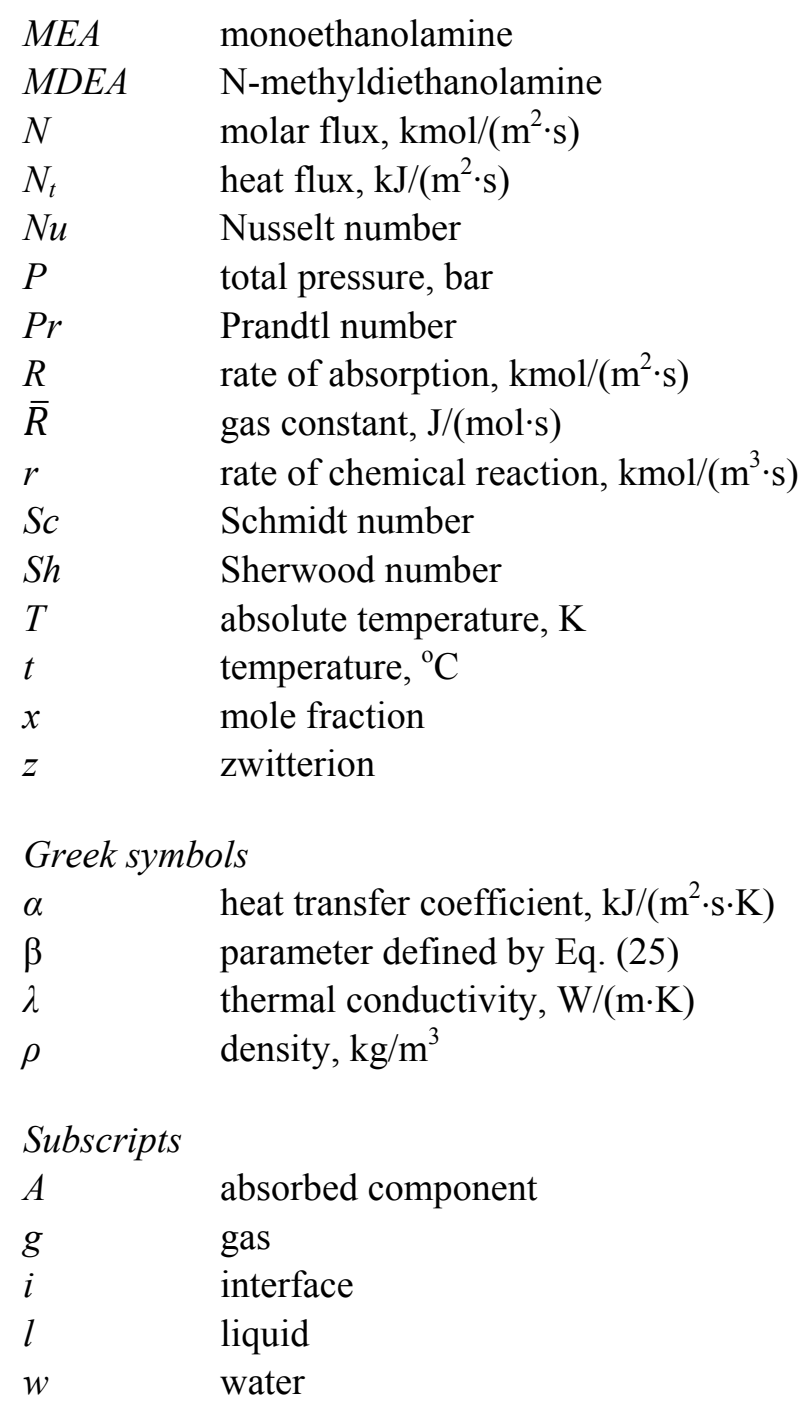

\section{REFERENCES}

Benitez-Garcia J., Ruiz-Ibanez G., Al.-Ghawas H., Sandall O.C., 1991. On the effect of basicity on the kinetics of $\mathrm{CO}_{2}$ absorption in tertiary amines. Chem. Eng. Sci., 46, 2927-2931. DOI: 10.1016/0009-2509(91)85161-P.

Critchfield J., Rochelle G.F., 1987. $\mathrm{CO}_{2}$ absorption into aqueous MDEA and MDEA/MEA solutions. AJCHE National Meeting, Houston, TX, 30.03.1987. Proceedings, Paper No 43e, 33.

Danckwerts P.V., 1979. The reaction of $\mathrm{CO}_{2}$ with ethanolamines. Chem. Eng. Sci., 34, 443-446. DOI: 10.1016/0009-2509(79)85087-3.

Donaldson T.L., Nguyen Y.N., 1980. Carbon dioxide reaction kinetics and transport in aqueous amine membranes. Ind. Engng. Chem. Fundam., 19, 260-266. DOI: 10.1021/1160075a005.

Haimour N., Bidarian A., Sandall O.C., 1987. Kinetics oh the reaction between carbon dioxide and methyldiethanolamine. Chem. Eng. Sci., 42, 1393-1398. DOI: 10.1016/0009-2509(87)85011-X.

Hobler T., 1962. Diffusional mass transport and absorbers. WNT, Warszawa, Chapter 3 (in Polish).

Hobler T., 1986. Heat transfer and exchangers. WNT, Warszawa, Chapter 3 (in Polish).

Horng S.Y., Li M.H., 2002. Kinetics of absorption of carbon dioxide into aqueous solutions of monoethanolamine+triethanolamine. Ind. Eng. Chem. Res., 41, 257-266. DOI: 10.1021/ie0106711.

Liao Ch.H., Li M.H., 2002. Kinetics of absorption of carbon dioxide into aquepus solutions of monoethanolamine + N-methyldiethanolamine. Chem. Eng. Sci., 57, 4569-4582. DOI: 10.1016/S0009-2509(02)00395-0.

Mandal B.P., Guha M., Biswas A.K., Bandyopadhyay, 2001. Removal of carbon dioxide by absorption in mixed amines: modelling of absorption in aqueous MDEA/MEA and AMP/MEA solutions. Chem. Eng. Sci., 56, 62176224. DOI: 10.1016/S0009-2509(01)00279-2. 
Mandal B.P., Biswas A.K., Bandyopadhyay, 2003. Absorption of carbon dioxide into aqueous blends of 2-amino2-methyl-1-propanol and diethanolamine. Chem. Eng. Sci., 58, 4137-4144. DOI: 10.1016/S00092509(03)00280-X.

Mimura T., Suda T., Iwaki I., Honda A., Kumazawa H., 1998. Kinetics of reaction between carbon dioxide and sterically hindered amines for carbon dioxide recovery from power plant flue gases. Chem. Eng. Comm., 170, 245-260. DOI:10.1080/00986449808912745.

Moniuk W., 2006. Absorption methods of synthesis and waste gases purification from acid component. Chem. Process Eng., 27, 9-34 (in Polish).

Moniuk W., Pohorecki R., 2000. Absorption of $\mathrm{CO}_{2}$ into aqueous solutions of N-methyldiethanolamine. Chem. Process Eng., 21, 183-197 (in Polish).

Moniuk W., Pohorecki R., Zdrójkowski A., 1997. Measurements of mass transfer coefficients in liquid phase in stirred reactor. Reports of the Faculty of Chemical and Process Engineering at the Warsaw University of Technology, 24, 91-111.

Pohorecki R., Moniuk W., Kruszewski J., 1990. The modelling of heat and mass transfer in the process of gas cleaning in ammonia synthesis. J. Eng. Physics, 59, 508-515 (in Russian).

Pohorecki R., Moniuk W., Kruszewski J., Laskowski L., 1978. Investigations of mass transfer kinetics in the flow gas-liquid apparatus in the process of $\mathrm{CO}_{2}$ absorption with chemical reaction from industrial gases. Research Report Institute of Chemical Engineering Warsaw University of Technology, 91.

Polish Patent Application, PL 391333 (26.05.2010).

Ramm W.M. 1976, Gas absorption. Chimija, Moscow, 139-143, Chapter 6 (in Russian).

Rangwala H.A., Morell B.R., Mather A.E., Otto F.D., 1992. Absorption of $\mathrm{CO}_{2}$ into aqueous tertiary amine/MDEA solutions. Can. J. Chem. Engng., 70, 482-490. DOI: 10.1002/cjce.5450700310.

Rinker E.B., Ashour S.S., Sandall O.C., 1995. Kinetics and modelling of carbon dioxide absorption into aqueous solutions of N-methyldiethanolamine. Chem. Eng. Sci., 50, 755-768. DOI: 10.1016/0009-2509(94)00444-V.

Sherwood T.K., Pigford R.L., 1952. Absorption and extraction. Mc Graw-Hill, New York.

Sun W. Ch., Yong Ch.B., Li M.H., 2005. Kinetics of the absorption of carbon dioxide ninto mixed aqueous solutions of 2-amino-2-methyl-1-1-propanol and piperazine. Chem. Eng. Sci., 60, 503-516. DOI: 10.1016/j.ces.2004.08.012.

Tomcej R.A., Otto F.D., 1989. Absorption of $\mathrm{CO}_{2}$ and $\mathrm{N}_{2} \mathrm{O}$ into aqueous solutions of methyldiethanolamine. AIChE J., 35, 861-864. DOI: DOI: 10.1002/aic.690350519.

Ume C.S., Ozturk M.C., Alper E., 2012. Kinetics of $\mathrm{CO}_{2}$ absorption by a blended aqueous amine solutions. Chem. Eng. Technol., 35, 464 - 468. DOI: 10.1002/ceat.201100394.

Vaidya P.D., Kenig E.Y., 2010. Termolecular kinetics model for $\mathrm{CO}_{2}$ alkanolamine reactions. An overview. Chem. Eng. Technol., 33, 1577 - 1581. DOI: 10.1002/ceat.201000050.

Versteeg G.F., Blauwhoff P.M.M., van Swaaij W.P.M., 1987. The effect of diffusivity on gas-liquid mass transfer in stirred vessels. Experiments at atmospheric and elevated pressures. Chem. Eng. Sci., 42, 1103-1119. DOI: 10.1016/0009-2509(87)80060-X.

Versteeg G.F., van Swaaij W.P.M., 1988. On the kinetics between $\mathrm{CO}_{2}$ and alkaloamines both in aqueous and nonaqueous solutions, II. Tertiary amines. Chem. Eng. Sci., 43, 587-591. DOI: 10.1016/0009-2509(88)87018-0.

Xiao J., Li Ch.W., Li M.H., 2000. Kinetics of absorption of carbon dioxide into aqueous solutions of 2-amino-2mthyl-1-propanol+monoethanolamine. Chem. Eng. Sci., 55, 161-175. DOI: 10.1016/S0009-2509(99)00303-6.

Zhang X., Zhang Ch.F., Qin Sh.J., Zheng Z.Sh., 2001. A kinetics study on the absorption of carbon dioxide into a mixed aqueous solution of methyldiethanolamine and piperazine. Ind. Eng. Chem. Res., 40, 3785-3791. DOI: 10.1021/ie000956i. 